\title{
DISTRIBUIÇÃO ESPACIAL E TEMPORAL DAS CHUVAS NO ESTADO DE SANTA CATARINA
}

\author{
Rafael Gotardo ${ }^{1}$ \\ Gustavo Antonio Piazza ${ }^{2}$ \\ Edson Torres ${ }^{3}$ \\ Dirceu Luis Severo ${ }^{4}$ \\ Vander Kaufmann ${ }^{5}$
}

\begin{abstract}
Resumo: A análise das tendências de precipitação é uma forma de compreender os impactos das mudanças do clima. Este trabalho analisa a variação espaço-temporal da precipitação no estado de Santa Catarina sob três perspectivas: dados médios; tendências sazonais; e projeção temática. Foram utilizados dados mensais de pluviometria obtidos da rede de estações hidrometeorológicas da Agência Nacional de Águas (ANA). As estações foram consistidas pelo método da Razão Normal. A avaliação dos dados consistiu na análise dos valores absolutos (médio, mínimos e máximos), análise de tendência, agrupamentos pelo Método de Ward e a distribuição espacial em SIG. O Oeste e Extremo Oeste são responsáveis pelos maiores índices pluviométricos do estado, sendo o verão a estação mais chuvosa. Tendências positivas foram verificadas em sete das oito mesorregiões administrativas do Estado.
\end{abstract}

Palavras-chave: Interpolação; Geoprocessamento; Geoestatística

\section{SPATIO-TEMPORAL RAIN DISTRIBUTION IN THE SANTA CATARINA STATE}

Abstract: Rainfall trend analysis is a way to understand impacts that may be caused by climate changes. This paper aims at analyzing rainfall spatio-temporal variations on the state of Santa Catarina under three main perspectives: averages; seasonal trends; and thematic rainfall projections. Monthly data from the pluviometric stations were obtained from the Nacional Water Agency (ANA) database. Consistency using normal ratio was performed over raw data. Data evaluation over absolute values (average, minimum and maximum), trend analysis, clusters by Ward method and spatial distribution were also executed. Extreme West and West regions are responsible for the highest rainfall indexes (monthly and year estimations), moreover summer season being the wettest season. Trend analysis revealed precipitation increase in seven of eight Administrative State regions.

Keywords: Interpolation, Geoprocessing, Geostatistics

\footnotetext{
${ }^{1}$ Prefeitura de Piratuba/Fundação Universidade Regional de Blumenau (FURB), Brasil, Engenheiro Agrônomo (Universidade do Oeste de Santa Catarina - UNOESC) e MSc em Engenharia Ambiental (FURB). Email: dr.rafaelgotardo@gmail.com

2 Programa de Pós-Graduação em Engenharia Ambiental (PPGEA) da Fundação Universidade Regional de Blumenau (FURB), Brasil, Engenheiro Ambietal (FURB) e MSc. em Engenharia Ambiental. Email: gustavoapiazza@gmail.com

3 PPGEA da FURB, Brasil, Engenheiro Químico (FURB) e MSc. Engenharia Ambiental (FURB). Email: ettotorres@gmail.com

${ }^{4}$ PPGEA e Centro de Operação do Sistema de Alerta de Cheias da Bacia do Rio Itajaí (CEOPS) da FURB, Brasil, Meteorologia (Universidade Federal de Pelotas - UFPEL), MSc. em Meteorologia (Instituto Nacional de Pesquisas Espaciais - INPE), Dr. em Meteorologia (INPE). Email: dirceuluis@gmail.com

5 PPGEA da FURB, Brasil, Química e Física (Universidade do Sul de Santa Catarina - UNISUL), MSc. em Engenharia Ambiental (FURB), Dr. em Recursos Hídricos e Saneamento Ambiental (Instituto de Pesquisas Hidráulicas IPH/UFRGS). Email: ambitec.amb@gmail.com
} 


\section{DISTRIBUCIÓN ESPACIAL Y TEMPORAL DE LAS LLUVAS EN EL ESTADO DE SANTA CATARINA}

Resumen: El análisis de tendencias de precipitación es una forma de comprender los impactos de los cambios climáticos. Este trabajo analiza la variación espacio-temporal de la precipitación en el estado de Santa Catarina bajo tres perspectivas: datos medios; tendencias estacionales; y proyección temática. Se utilizaron datos mensuales de pluviometría obtenidos de la red de estaciones hidrometeorológicas de la Agencia Nacional de Aguas (ANA). Las estaciones fueron consistidas por el método de la razón normal. La evaluación de los datos consistió en el análisis de los valores absolutos (medio, mínimos y máximos), análisis de tendencia, agrupamientos por el método de Ward y la distribución espacial en SIG. El Oeste y Extremo Oeste son responsables por los mayores índices pluviométricos del estado, siendo el verano la estación más lluviosa. Tendencias positivas fueron verificadas en siete de las ocho mesorregiones administrativas del Estado.

Palabras clave: Interpolación, Geoprocesamiento, Geoestadística

\section{INTRODUÇÃO}

As mudanças climáticas têm sido um dos temas mais debatidos dentro da área científica nas últimas décadas. O efeito dele é sentido nas variáveis descritoras do clima, como radiação, temperatura e evapotranspiração (WANDERLEY et al., 2014; SALVIANO et al., 2016). Relatórios passados (2007) e recentes (2013) do IPPC discutem sobre a anormalidade do comportamento da temperatura média da superfície terrestre e suas consequências sobre a frequência e a intensidade dos eventos extremos nas regiões tropicais. Para Sanches et al., (2014), esses eventos climáticos extremos são evidências da alteração do clima tanto em nível global, regional e local. Nessa mesma perspectiva Marengo (2007), aponta os países menos desenvolvidos da região tropical e subtropical como aqueles que mais sofrem com as mudanças do clima. De acordo com Groisman et al. (2005) o Brasil teve um aumento significativo no volume precipitado a partir de 1950. Dentre as áreas impactadas pelas mudanças no clima no Brasil, a agroeconomia tem recebido destaque, pois depende exclusivamente do comportamento da meteorologia e do clima (EMBRAPA, 2011). As alterações e perdas na produtividade agrícola causadas pelas mudanças climáticas já vem sendo debatidas por outros 
autores como Assad e Luchiari Jr. (1989), Siqueira et al. (1994) e Pinto et al. (2001), no entanto, pouca atenção tem sido fornecida a sua gestão e planejamento futuro.

Para entender como as mudanças estão modificando os elementos do clima, diversos estudos têm focado no comportamento da temperatura e da precipitação (PAIVA; CLARKE, 1995; GROPPO et al., 2001; MARENGO; ALVES, 2005; HAYLOCK et al., 2006; FOLHES; FISCH, 2006; OBREGÓN; MARENGO, 2007; SILLMANN; ROECKNER, 2008; BLAIN, 2009; BIGGS; ATKINSON, 2011; MARENGO et al., 2012; SANCHES et al., 2014; VALVERDE; MARENGO, 2014; SALVIANO et al., 2016). Resultados apontam principalmente para tendências, entendidas como alterações (acréscimo ou decréscimo) dos valores médios dentro do período de registro. Para Mendonça (2006), variações dos componentes do ciclo hidrológico têm atuado de forma diferenciada sobre a distribuição de chuva no país. Para Villarini (2011) tais modificações podem estar associadas às oscilações naturais, como intensificação solar, embora já exista comprovação da ação antrópica para estas mudanças (MARENGO, 2007). No Relatório do IPCC de 2014, foi afirmado que 95\% do aumento da temperatura média global são influenciados por ações humanas.

A chuva é uma das formas de precipitação de maior importância dentro do ciclo hidrológico. A ocorrência ou a falta dela está relacionada a fenômenos meteorológicos e climáticos. De acordo com Keller Filho et al. (2006) a distribuição espacial das precipitações e sua variação ao longo do tempo são formas de determinar o comportamento climático das regiões. Seu comportamento na região do Sul do Brasil está relacionado a eventos de meso e macro escalas, como o El Niño e La Niña, diretamente ligados as mudanças oceânicas e atmosféricas da região equatorial do oceano Pacífico Tropical. As irregularidades climáticas não somente ocasionam a falta ou o excesso de um elemento meteorológico, mas implica também na alteração de sua distribuição espaço-temporal. As perturbações ocorridas na atmosfera têm afetado os padrões climáticos de cada região e, consequentemente, as atividades ali desenvolvidas (FERREIRA, 2002). Neste contexto, fica evidente a importância dos estudos 
de ocorrência e distribuição das precipitações no suporte a tomada de decisão para o planejamento das atividades econômicas a nível local e regional.

Para análises de distribuição espacial, Sistemas de Informação Geográfica (SIG) são essenciais (MELLO et al., 2008; MARCUZZO e MELO, 2011). Santa Catariana já conta com uma base consolidada de estudos de comportamento e distribuição espacial do regime pluviométrico, podendo citar os estudos de Back (2001), Pandolfo (2002) e Back et al. (2016), sem considerar a bibliografia acadêmica (teses e dissertações). Sua atualização e revisão, no entanto, se fazem constantemente necessários no sentido de determinar novas variações de comportamento e medidas de amortecimento referente as mudanças no clima. Na agricultura, o conhecimento antecipado das condições locais de solo, radiação solar e precipitação, bem como suas variações ao longo de um ciclo de cultivo, são essenciais para a obtenção de rendimentos satisfatórios.

Assim como em outras regiões do país, algumas regiões de Santa Catarina também tem sido alvo das mudanças do clima, principalmente relacionado a períodos de estiagem e sucessivas ocorrências de eventos extremos de precipitação (PIAZZA et al., 2016). Estas variações podem determinar anos favoráveis e desfavoráveis para a produção agrícola, afetando diretamente a economia estadual. Este estudo teve como objetivo a determinação da variação espaço-temporal da precipitação para o estado de Santa Catarina por meio de três objetivos específicos: (i) estabelecer valores médios das precipitações anuais para o estado de Santa Catarina e suas mesorregiões; (ii) identificar tendências sazonais das precipitações; e (iii) distribuir as informações em mapas temáticos de projeções futuras usando um SIG.

\section{ÁREA DE ESTUDO}

O estado de Santa Catarina está localizado na região Sul do Brasil (Figura 1). Ele tem uma área de $95.442,9 \mathrm{~km}^{2}$, representando $1,12 \%$ do território nacional e $16,61 \%$ da região Sul. É 
composto por 295 municípios, divididos em meso e microrregiões, tendo como capital Florianópolis (IBGE, 2016). A dinâmica da precipitação de Santa Catarina é associada a geomorfologia e ao relevo (MONTEIRO e FURTADO, 1995; MONTEIRO, 2001). A geomorfologia do estado é caracterizada por planícies litorâneas nas zonas baixas e planalto nas zonas altas. A divisão destes dois ambientes é determinada pela Serra Geral, que também é responsável por drenar as águas. De acordo com a classificação de Köppen, Santa Catarina apresenta um clima subtropical úmido mesotérmico, variando de $0^{\circ} \mathrm{C}$ nas zonas altas no inverno e $35^{\circ} \mathrm{C}$ na região litorânea no verão (HERRMANN, 1997). A ocorrência de precipitações é diferenciada por região. Segundo Monteiro (2001), nas encostas de montanhas (como nos vales), as precipitações são mais abundantes devido à elevação do ar úmido e quente, que favorece a formação de nuvens cumuliformes. No planalto e no oeste do estado, no entanto, são observadas temperaturas negativas, favorecidas pelo efeito da altitude as chuvas são mais volumosas quando comparado às zonas litorâneas (MONTEIRO, 2001). 
Figura 1 - Localização da área de estudo e das estações pluviométricas utilizadas para o estado de Santa Catarina.

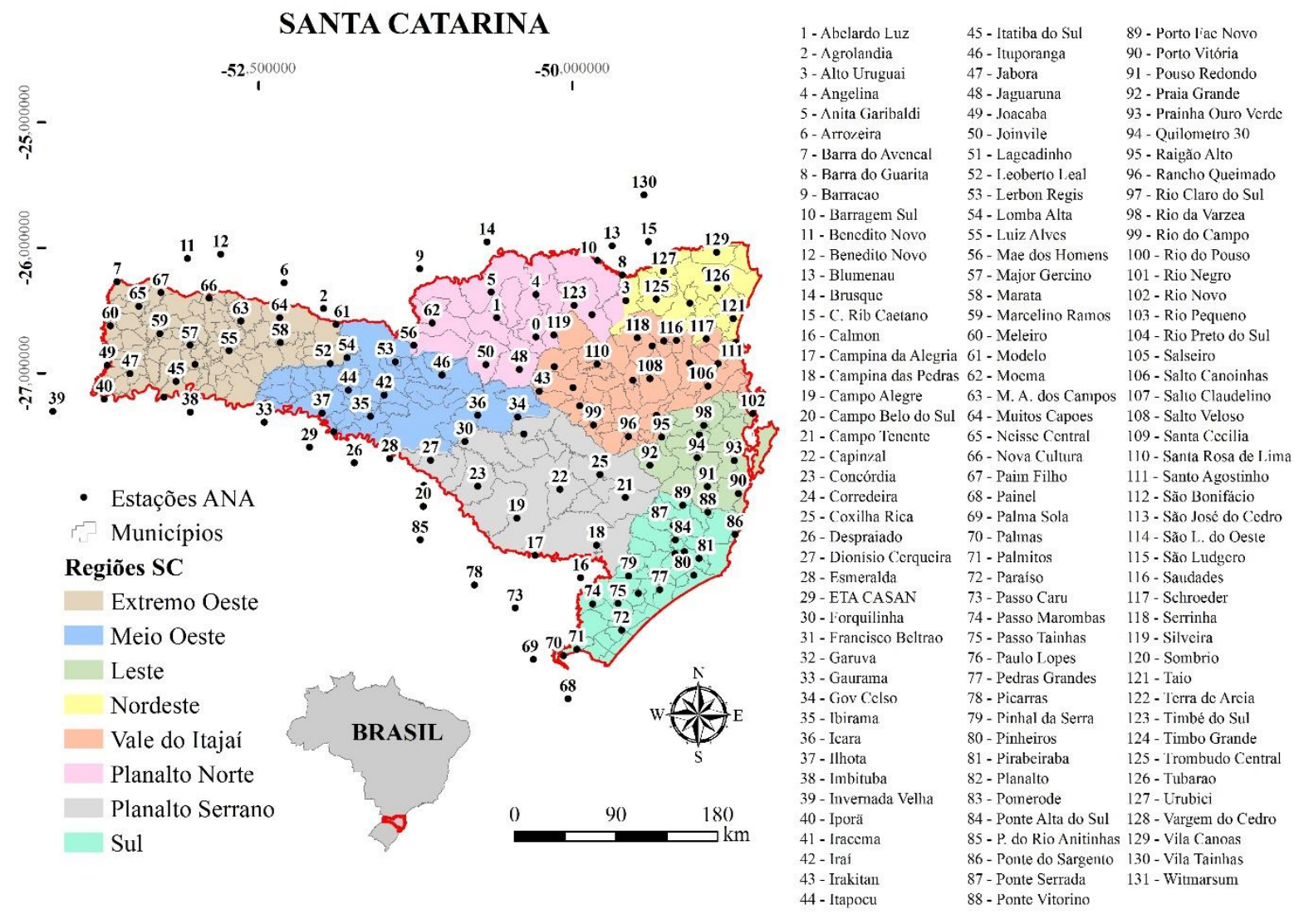

\section{METODOLOGIA}

Foram utilizados dados de precipitação de estações pluviométricas distribuídas em Santa Catarina (Figura 1) além de estações de apoio no entorno do estado, utilizadas na interpolação. Para melhor entendimento das análises da distribuição de chuvas, o estado foi caracterizado em oito mesorregiões (SANTA CATARINA, 2009) (Figura 1 e Tabela 1), duas regiões a mais do que classificação tradicional. As regiões Sul, Vale do Itajaí e Nordeste foram consideradas regiões mais densas em relação a rede hodrometeorológica. As regiões Planalto Serrano e Oeste foram as menos densas. Isso se deve ao fato de que regiões litorâneas, por 
apresentarem uma maior quantidade de centros urbanos, apresentam um número mais elevado de estações para fins científicos.

Dados diários de pluviometria foram obtidos na rede de estações hidrometeorológicas da Agência Nacional de Águas (ANA), disponíveis no endereço eletrônico do HIDROWEB. As estações foram pré-selecionadas em ambiente SIG (Sistema de Informação Geográfica, ArcGIS 10.3) considerando a distribuição espacial de cada região. Em seguida, dados pluviométricos foram tabulados em ambiente Excel de acordo com a série temporal de dados. Devido à baixa quantidade e qualidade dos dados passados, foi definido o período de análise dos dados entre 1975 a 2014.

Tabela 1 - Estações pluviométricas por região do estado de Santa Catarina.

\begin{tabular}{lccc}
\hline Região & Área $\left(\mathbf{k m}^{\mathbf{2}}\right)$ & Número de estações & Estações por $\mathbf{k m}^{\mathbf{2}}$ \\
\hline Extremo Oeste & 15.007 & 15 & 0,0010 \\
Meio Oeste & 14.059 & 12 & 0,0009 \\
Leste & 7.191 & 8 & 0,0011 \\
Nordeste & 6.651 & 9 & 0,0014 \\
Vale do Itajaí & 13.317 & 20 & 0,0015 \\
Planalto Norte & 13.076 & 13 & 0,0010 \\
Planalto Serrano & 16.504 & 9 & 0,0005 \\
Sul & 9.588 & 15 & 0,0016 \\
\hline
\end{tabular}

Os dados pluviométricos obtidos do sistema nacional são em parte consistidos, no entanto, a partir do ano de 2000, grande parte dos dados encontra-se sem consistência e com presença de falhas. Para isso, foi realizado o preenchimento das falhas dos dados brutos por meio do Método da Razão Normal descrito por Singh (1994) e Silva et al. (2007). O Método da Razão Normal expresso a seguir, consiste em calcular as falhas de uma estação em virtude da média ponderada das estações vizinhas.

$$
P_{X}=\frac{1}{M} \sum_{I=1}^{M}\left[\frac{N_{X}}{N_{I}}\right] P_{I}
$$

Onde, Px - estação sem dados; P1 - estação utilizada para a estimativa; Nx precipitação anual da estação "X”; $\mathrm{Ni}$ - precipitação anual das estações vizinhas; $\mathrm{M}$ - número de estações vizinhas. 
Após o preenchimento das falhas, fez-se a análise dos dados das estações de cada uma das mesorregiões separadamente, em âmbito diário, mensal e anual. Dentro destas análises foram trabalhados os índices estatísticos de média, máximo e mínimo, e avaliado o comportamento das precipitações durante os últimos anos, no sentido de identificar tendências das precipitações. Para isso, realizou-se uma análise por meio da linha de tendência, ajustado por função linear. Tendo em vista que a equação da reta é dada como $y=a x+b$, "a" corresponde ao coeficiente angular da reta. Assim, se a > 0 pode-se dizer que a tendência é crescente, caso contrário $(\mathrm{a}<0)$ a tendência é decrescente. Ao realizar esse procedimento, o valor do coeficiente de determinação $\left(\mathrm{R}^{2}\right)$ foi obtido como uma medida da qualidade do ajuste efetuado. Maiores informações sobre a análise da linha de tendência encontram-se em Piazza et al. (2016).

Com o objetivo de avaliar a distribuição espacial das chuvas no estado de Santa Catarina, os dados consistidos das estações pluviométricas foram inseridos e trabalhados em Sistema de Informação Geográfica, por meio do software ArcGIS 10.3. O processamento dos dados ocorreu por meio da ferramenta análise geoestatística (Geostatistical Analysis), pelo método de interpolação da Krigagem (Kriging) do tipo Ordinário (Ordinary), com posterior otimização do modelo (disponível no software). Sobre as médias anuais das mesorregiões foi realizada uma análise de agrupamentos (Cluster Analysis) por meio do método de Ward (1963), que é um método aglomerativo hierárquico e tem como o objetivo de formar grupos através da maximização da homogeneidade. Grupos são formados com base na menor soma dos quadrados entre dois grupos hipotéticos (HAIR et al., 2005; MINIGOTI, 2005). De acordo com Malhotra (2006) a análise de cluster é eficiente no agrupamento de dados de comportamento semelhante. Os agrupamentos foram executados no software PAST v 2.14 (HAMMER et al., 2001).

\section{RESULTADOS E DISCUSSÕES}

Os valores médios de precipitação anual obtidos com base nos dados históricos ocorridos entre os anos de 1975 a 2014 nas 131 estações pluviométricas distribuídas no estado de Santa Catarina, apresentaram uma variação bianual entre picos positivos e negativos da 
precipitação (Figura 2). Esta variabilidade também já foi percebida por Andrade et al. (1999) em um estudo sobre a precipitação do estado de Santa Catarina.

A precipitação média anual (1975-2014) em Santa Catarina foi de aproximadamente $1748 \mathrm{~mm}$. ano $^{-1}$. O maior volume médio precipitado ocorreu no ano de $1983 \mathrm{com} 2673 \mathrm{~mm}$.ano ${ }^{-}$ 1, variando de 2237 mm.ano ${ }^{-1}$ na região Sul e 3095 mm.ano ${ }^{-1}$ no Extremo Oeste. Por outo lado, o menor volume precipitação ocorreu em 2006, variando de 1074 mm.ano ${ }^{-1}$ no Planalto Norte e $1533 \mathrm{~mm} \cdot \mathrm{ano}^{-1}$ no Extremo Oeste. O Extremo Oeste em ambos os casos registrou os maiores índices pluviométricos, tanto para dados máximos como para mínimos. Pela análise da linha de tendência foi verificada uma tendência positiva nas médias anuais de precipitação (1975-2014), com $12,8 \%$ de aumento no período estudado para Santa Catarina.

Figura 2 - Distribuição temporal dos dados anuais de precipitação para o estado de Santa Catarina entre 1975 a 2014.

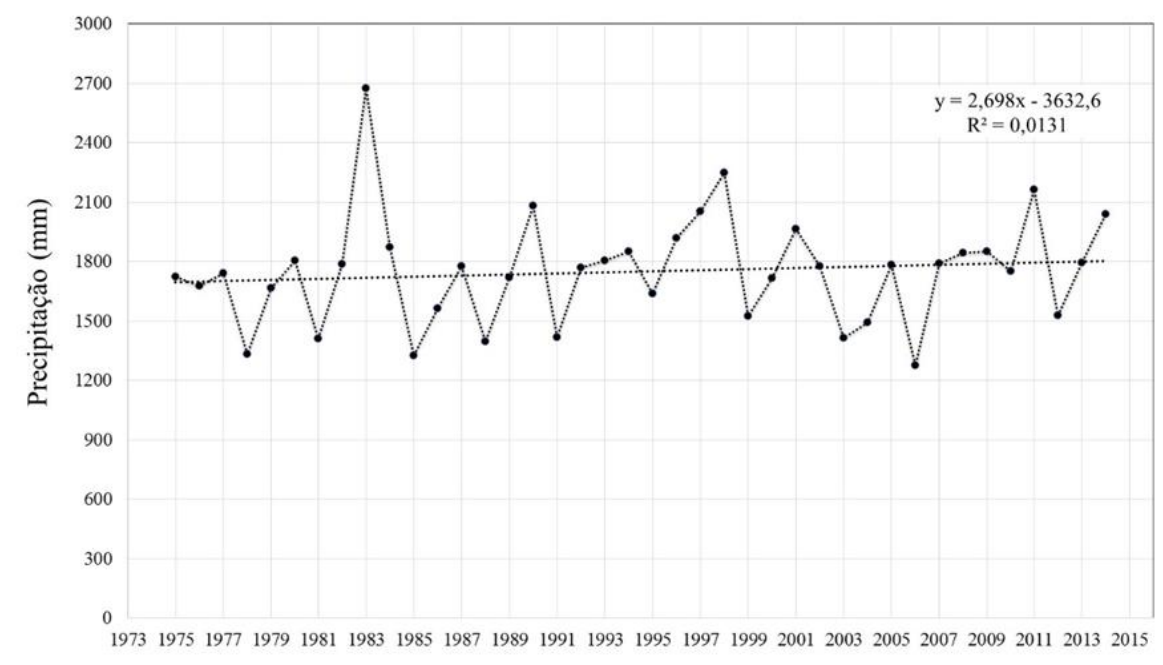

A análise da média anual das regiões elencou o Extremo Oeste com a maior precipitação (1955,9 mm.ano $\left.{ }^{-1}\right)$ e o Sul com a menor (1627,8 mm.ano ${ }^{-1}$ ) (Tabela 2). O Extremo Oeste novamente apresentou o maior registro, com 3094,6 mm.ano ${ }^{-1}$, para a estação de Dionísio Cerqueira (Código ANA 2653002). O Extremo Oeste apresentou à maior média mensal com 
166,95 mm.mês ${ }^{-1}$ e o Sul a menor (134,92 mm.mês $\left.{ }^{-1}\right)$. As menores quantidades mensais foram obtidas para a região do Vale do Itajaí na estação de Witmarsun (Código ANA 2649053) em abril de 1978 e o maior registro para o Extremo Oeste na estação de Modelo (Código ANA 2653003) em outubro de 2001 (Tabela 2).

Tabela 2 - Precipitação média anual e mensal das regiões no estado de Santa Catarina.

\begin{tabular}{lccc|ccc}
\hline \multicolumn{1}{c}{ Região } & $\begin{array}{c}\text { Média } \\
\text { anual }\end{array}$ & $\begin{array}{c}\text { Mínimo } \\
\text { anual } \\
\text { registrado }\end{array}$ & $\begin{array}{c}\text { Máximo } \\
\text { anual } \\
\text { registrado }\end{array}$ & $\begin{array}{c}\text { Média } \\
\text { mensal }\end{array}$ & $\begin{array}{c}\text { Mínimo } \\
\text { mensal } \\
\text { registrado }\end{array}$ & $\begin{array}{c}\text { Máximo } \\
\text { mensal } \\
\text { registrado }\end{array}$ \\
\cline { 2 - 6 } & \multicolumn{7}{c}{$\mathbf{( m m )}$} \\
\hline Extremo Oeste & 1955,9 & 1238,9 & 3094,6 & 166,95 & 1,70 & 1869,00 \\
Meio Oeste & 1833,9 & 1269,9 & 2887,3 & 153,63 & 1,80 & 977,90 \\
Planalto Norte & 1663,6 & 1054,8 & 2444,8 & 139,80 & 2,10 & 736,30 \\
Nordeste & 1813,8 & 1211,0 & 2592,5 & 158,55 & 2,30 & 1523,00 \\
Planalto Serrano & 1693,0 & 1223,7 & 2550,9 & 137,32 & 1,60 & 811,80 \\
Vale do Itajaín & 1657,2 & 1110,7 & 2701,6 & 138,75 & 1,00 & 1001,20 \\
Leste & 1743,2 & 1155,7 & 2877,8 & 145,71 & 2,80 & 928,78 \\
Sul & 1627,8 & 1238,1 & 2237,2 & 134,92 & 3,10 & 809,60 \\
\hline Média & $\mathbf{1 7 4 8 , 5}$ & $\mathbf{1 1 8 7 , 8}$ & $\mathbf{2 6 7 3 , 3}$ & $\mathbf{1 4 6 , 9 5}$ & $\mathbf{2 , 0 5}$ & $\mathbf{1 0 8 2 , 2 0}$ \\
\hline
\end{tabular}

Em relação às médias mensais, o estado de Santa Catarina apresentou em média 146,95 mm.mês ${ }^{-1}$, sendo o mês de janeiro (verão) o que apresentou a maior média (189,6 mm.mês ${ }^{-1}$ ) e o mês de abril (primavera) a menor (116,0 mm.mês ${ }^{-1}$ ) (Figura 3). Este resultado é semelhante a Baldo et al. (1998), que estudando aspectos estatísticos da precipitação na bacia do Itajaí, também encontrou ocorrência de maior precipitação nos meses referentes a estação do verão (dezembro, janeiro, fevereiro e março). Outubro, de acordo com a Figura 3, também apresentou precipitações acima da média. Vale lembrar, que outubro de 2008 é um evento climático histórico de Santa Catarina, mês em que ocorram desastres em várias regiões do Estado devido aos altos índices pluviométricos. A Tabela 3 apresenta a distribuição mensal da precipitação e o comportamento ao longo dos anos (1975-2014), assim como taxas de aumento e redução.

Figura 3 - Distribuição temporal da precipitação média mensal no estado de Santa Catarina entre os anos de 1975 a 2014. 


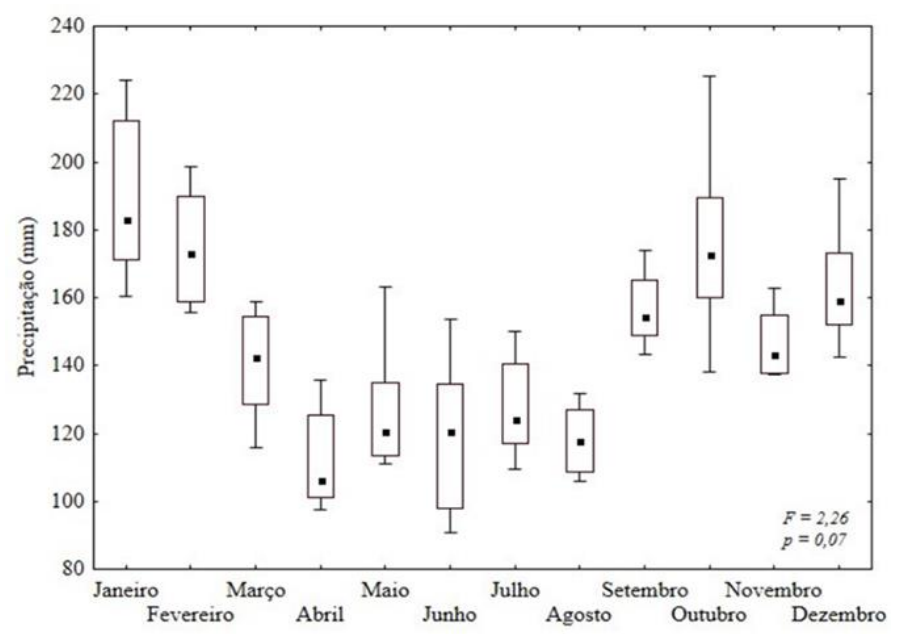

Tabela 3 - Distribuição temporal e regressão linear da precipitação mensal no estado de Santa Catarina entre os anos de 1975 a 2014.

\begin{tabular}{lcccccc}
\hline Meses & Média & Máxima & Mínima & Regressão linear & $\mathbf{R}^{\mathbf{2}}$ & Taxas (\%)* \\
\hline Janeiro & 193,26 & 297,73 & 58,94 & $\mathrm{y}=0,9014 \mathrm{x}+174,79$ & 0,0345 & $20,01 \%$ \\
Fevereiro & 172,69 & 284,26 & 68,84 & $\mathrm{y}=0,3539 \mathrm{x}+165,44$ & 0,0058 & $8,32 \%$ \\
Março & 140,80 & 241,57 & 59,72 & $\mathrm{y}=0,3458 \mathrm{x}+133,71$ & 0,0085 & $10,60 \%$ \\
Abril & 116,04 & 234,14 & 13,52 & $\mathrm{y}=0,8477 \mathrm{x}+98,66$ & 0,0402 & $33,22 \%$ \\
Maio & 126,53 & 326,55 & 24,02 & $\mathrm{y}=-0,5364 \mathrm{x}+137,52$ & 0,0071 & $-15,27 \%$ \\
Junho & 118,79 & 359,53 & 37,35 & $\mathrm{y}=1,1537 \mathrm{x}+95,13$ & 0,0502 & $46,73 \%$ \\
Julho & 127,86 & 541,95 & 16,43 & $\mathrm{y}=-0,2793 \mathrm{x}+133,59$ & 0,0016 & $-8,17 \%$ \\
Agosto & 128,10 & 302,47 & 23,82 & $\mathrm{y}=-0,3823 \mathrm{x}+125,93$ & 0,0044 & $-11,88 \%$ \\
Setembro & 156,69 & 305,07 & 60,31 & $\mathrm{y}=1,3453 \mathrm{x}+129,11$ & 0,0713 & $40,22 \%$ \\
Outubro & 165,99 & 340,44 & 86,85 & $\mathrm{y}=0,3617 \mathrm{x}+168,57$ & 0,0057 & $8,35 \%$ \\
Novembro & 146,43 & 285,36 & 68,44 & $\mathrm{y}=-0,639 \mathrm{x}+159,52$ & 0,0209 & $-15,69 \%$ \\
Dezembro & 161,08 & 289,83 & 41,50 & $\mathrm{y}=0,1089 \mathrm{x}+158,85$ & 0,0007 & $2,67 \%$ \\
\hline Média & 146,95 & 317,41 & 46,64 & & - & - \\
\hline
\end{tabular}

*taxa de aumento ou redução da precipitação ao longo dos anos (1975-2014).

Os meses de maio, junho, agosto e novembro apresentaram redução na precipitação, sendo novembro $(15,69 \%)$ e maio $(15,27 \%)$ as maiores reduções no volume precipitado. Por outro lado, junho $(46,73 \%)$, setembro $(40,22 \%)$ e abril $(33,22 \%)$ foram responsáveis pelos maiores aumentos no volume precipitado. A média mensal de aumento para o estado de Santa Catarina foi de $9,93 \%$. 
A análise da sazonalidade colocou o verão como a estação responsável pela maior média (499,32 mm) e o inverno com a menor (364,74 mm) (Figura 4). Esse resultado já era esperado tendo em vista o comportamento da chuva regional, podendo ser constatado também em outros estudos como Monteiro (2001), que explica no período do verão devido a ocorrência das frentes frias é intensificada a convecção tropical resultando em tempestades diárias (chuvas de alta intensidade em curtos períodos).

Figura 4 - Precipitação média em cada uma das estações climáticas para as diferentes regiões do estado de Santa Catarina.

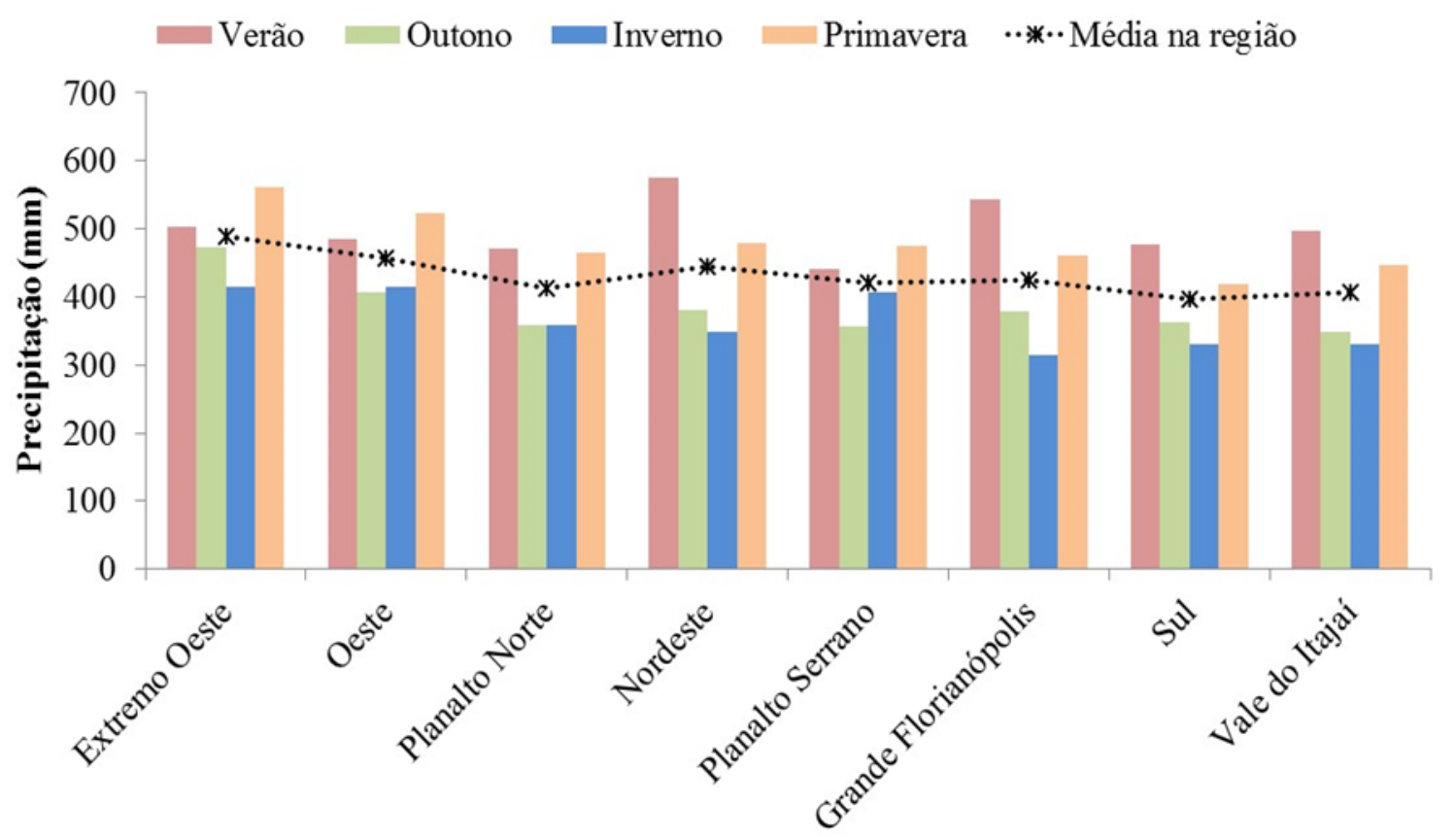

A estação da primavera e do outono apresentaram em média 479,11 e 383,37 mm, respectivamente. Com a análise das mesorregiões, pode-se observar que o Nordeste é a região que possui os maiores índices pluviométricos durante os períodos de verão com uma média de 543,96 mm, enquanto o Planalto Serrano apresentou o menor volume (440,22 mm). Este resultado condiz com o estudo de Teixeira e Satyamurty (2007) que encontraram elevados volumes de precipitação no verão para as regiões litorâneas e no Vale do Itajaí. Segundo Seluchi 
et al. (2009) os altos índices pluviométricos das regiões litorâneas estão ligados a ocorrência das precipitações orográficas, cujo mecanismo é favorecido pela atuação do sistema de alta pressão do Atlântico Sul que desloca o ar úmido marítimo para o continente. Em relação à primavera, o Extremo Oeste foi responsável pelo maior volume $(562,05 \mathrm{~mm})$ e o Sul pelo menor (419,40 mm). O inverno apresentou os maiores índices para as regiões Extremo Oeste $(414,44$ $\mathrm{mm}$ ) e o Oeste $(414,48 \mathrm{~mm})$, e o menor para o Leste com 314,68 mm. O período de outono a maior taxa de precipitação foi na região do Extremo Oeste com um volume de 473,48 mm e a menor para a região do Vale do Itajaí com 349,20 mm.

Para melhor compreender o comportamento anual da precipitação, os dados também foram analisados em decêndios (Tabela 4). Os resultados mostraram que a precipitação apresenta uma redução nos primeiros dois decênios (1974-1984-1994), aumento no seguinte (1995-2004) e redução no período subsequente (2005-2014). Esse resultado demonstra a cautela a ser tomada quando se analisada séries históricas, ou seja, dependendo do filtro (ano de início do registro) diferentes tendências podem aparecer.

Tabela 4 - Valores médios de precipitação dos decênios analisados para as regiões analisadas no Estado de Santa Catarina.

\begin{tabular}{|c|c|c|c|c|c|c|c|c|c|c|c|}
\hline \multirow{2}{*}{ Região } & \multirow{2}{*}{ Geral } & \multicolumn{8}{|c|}{ Média Anual (mm) } & \multirow{2}{*}{\multicolumn{2}{|c|}{$\begin{array}{c}\text { Projeção } \\
\text { 2015-2024 }\end{array}$}} \\
\hline & & \multicolumn{2}{|c|}{ 1975-1984 } & \multicolumn{2}{|c|}{ 1985-1994 } & \multicolumn{2}{|c|}{ 1995-2004 } & \multicolumn{2}{|c|}{ 2005-2014 } & & \\
\hline Extremo Oeste & 2003 & 19734 & $-1,5 \%$ & 1971 & $-1,6 \%$ & 2059 & $2,8 \%$ & 2010 & $-0,3 \%$ & 2030 & $1,3 \%$ \\
\hline Oeste & 3 & 1840 & $-0,2 \%$ & 1744 & $-5,4$ & 1917 & 4,0 & 1873 & -1 , & 1920 & $4,2 \%$ \\
\hline Planalt & 1678 & 17 & $1,6 \%$ & 1604 & $-4,4$ & 1697 & $\mathbf{1}$, & 1704 & $\%$ & 1738 & $3,6 \%$ \\
\hline Nor & 1902 & 1991 & $3,6 \%$ & 1837 & $-3,4 \%$ & 1930 & $1,4 \%$ & 1852 & $3,6 \%$ & 1842 & $3,2 \%$ \\
\hline Planal & 1648 & 1589 & $-3,5 \%$ & 1565 & $-5,0 \%$ & 1692 & $2,7 \%$ & 174 & $-5,8 \%$ & 1821 & $10,4 \%$ \\
\hline Vale do It & 1665 & 1679 & $\mathbf{0 , 8 \%}$ & 1594 & $-4,2 \%$ & 1641 & $1,4 \%$ & 1746 & $-2,8 \%$ & 1803 & $8,3 \%$ \\
\hline Leste & 17 & 1827 & $4,5 \%$ & 1547 & $-9,5 \%$ & 1723 & $1,4 \%$ & 1897 & $-5,5 \%$ & 2021 & $15,6 \%$ \\
\hline Sul & 1619 & 1624 & $\mathbf{0 , 3 \%}$ & 1480 & $-8,6 \%$ & 1667 & $3,0 \%$ & 1704 & $-3,3 \%$ & 1788 & $10,5 \%$ \\
\hline Média & 1763 & 1779 & $-0,4 \%$ & 1668 & $-5,3 \%$ & 1791 & $2,2 \%$ & 1816 & $-1,6 \%$ & 1870 & $7,1 \%$ \\
\hline
\end{tabular}

Legenda: $(\%)$ = valor em relação à média geral.

As mesorregiões que tiveram aumento sequencial nos decênios de 1995 a 2014 foram Planalto Norte e o Nordeste. A maior porcentagem de acréscimo ocorreu no período entre 19952004 na região Sul e no período de 2005-2014 na região Nordeste. Em compensação houve 
regiões que tiveram redução nos índices pluviométricos em relação ao período de 2005-2014, sendo elas: Extremo Oeste, Oeste, Planalto Serrano, Vale do Itajaí, Leste e Sul. De acordo com Andrade et al. (1999) a variabilidade da precipitação ocorrida na região Nordeste sofre influência de uma dinâmica de sistemas convectivos associados a uma ciclogênese na parte costeira do Estado. Na análise de dois decênios (Tabela 5), as tendências foram evidenciadas. Ali, apenas a região Nordeste apresentou tendência de projeção negativa em relação aos períodos de 1975-1994 a 1995-2014. Todas as outras mesorregiões apresentaram tendência positiva, sendo a região do Planalto Serrano com a maior diferença entre os períodos analisados $(140,75 \mathrm{~mm})$.

Tabela 5 - Valores médios de precipitação dos dois decênios analisados e projeção para precipitações futuras para as regiões analisadas no Estado de Santa Catarina.

\begin{tabular}{|c|c|c|c|c|c|c|c|c|}
\hline Região & Geral & \multicolumn{2}{|c|}{ 1975-1994 } & \multicolumn{2}{|c|}{ 1995-2014 } & \multirow{2}{*}{$\frac{\text { Diferença (mm) }}{62,22}$} & \multicolumn{2}{|c|}{ Projeção (2015-2034) } \\
\hline Extremo Oeste & 2003 & 1972 & $-1,6 \%$ & 2034 & $1,6 \%$ & & 2097 & $4,7 \%$ \\
\hline Oeste & 1843 & 1792 & $-2,8 \%$ & 1895 & $2,8 \%$ & 103,08 & 1998 & $8,4 \%$ \\
\hline Planalto Norte & 1678 & 1654 & $-1,4 \%$ & 1701 & $1,4 \%$ & 46,40 & 1747 & $4,1 \%$ \\
\hline Nordeste & 1902 & 1914 & $0,6 \%$ & 1891 & $-0,6 \%$ & $-22,93$ & 1868 & $-1,8 \%$ \\
\hline Planalto Serrano & 1648 & 1577 & $-4,3 \%$ & 1718 & $4,3 \%$ & 140,75 & 1859 & $12,8 \%$ \\
\hline Vale do Itajaí & 1665 & 1637 & $-1,7 \%$ & 1693 & $1,7 \%$ & 56,64 & 1750 & $5,1 \%$ \\
\hline Leste & 1748 & 1687 & $-3,5 \%$ & 1810 & $3,5 \%$ & 122,84 & 1933 & $10,5 \%$ \\
\hline Sul & 1619 & 1552 & $-4,1 \%$ & 1685 & $4,1 \%$ & 133,49 & 1819 & $12,4 \%$ \\
\hline Média & & 1723,2 & & 1803,5 & & 80,31 & 1883,8 & \\
\hline
\end{tabular}

Legenda: $(\%)$ = valor em relação à média geral.

O comportamento de tendência negativa para os primeiros períodos para a análise na escala de um e dois decênios das mesorregiões (Tabelas 4 e 5) se deve ao fato de que os anos de 1983 e 1984 foram marcados por altos índices pluviométricos em todo o estado, influenciando a média pluviométrica do período (Figura 5). 
Figura 5 - Médias e desvios padrões das precipitações anuais em Santa Catarina.

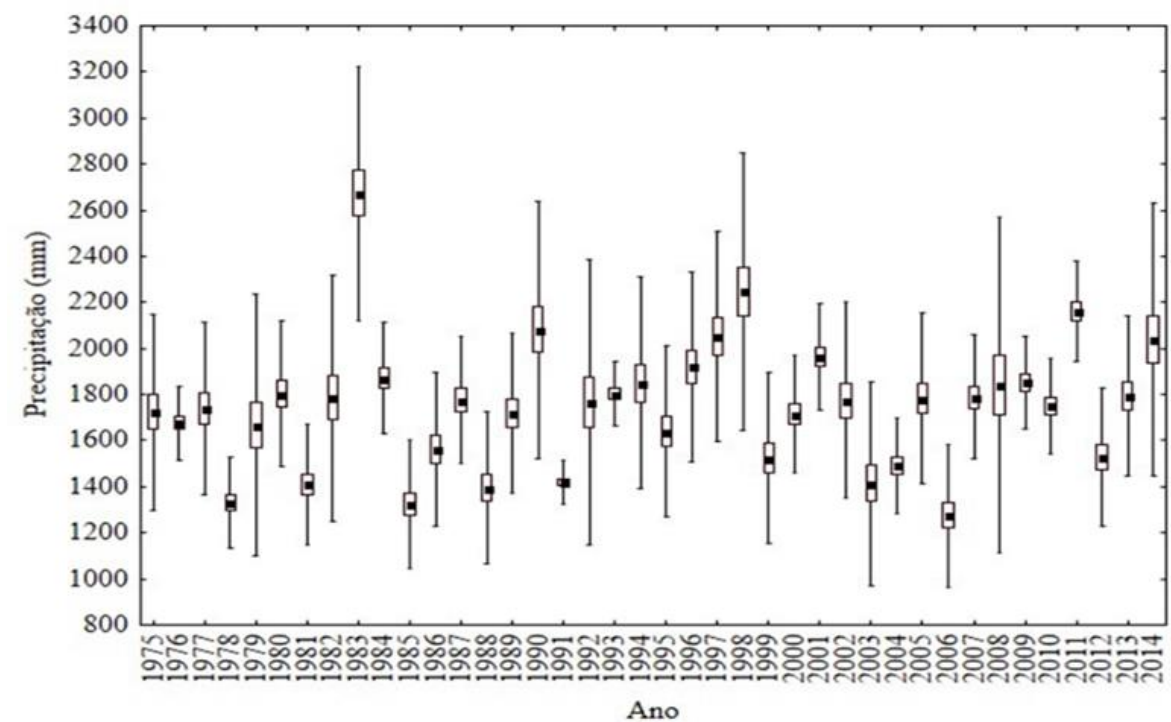

Vale lembrar, que 1982 e 1983 foram anos de ocorrência de El Niño. Outro ano a ser destacado é 2008 (responsável por um dos maiores desvios-padrão, Figura 5), marcado pela maior tragédia natural já registrada na região sul do Brasil (AUMOND; SEVEGNANI, 2009) e consequentemente alterando o comportamento da análise dos decênios. A Figura 6 traz o comportamento da precipitação em cada uma das mesorregiões do estado, comprovando o aumento na precipitação estabelecido na Tabela 4. 
Figura 6 - Precipitação anual das regiões de Santa Catarina (1975-2014).
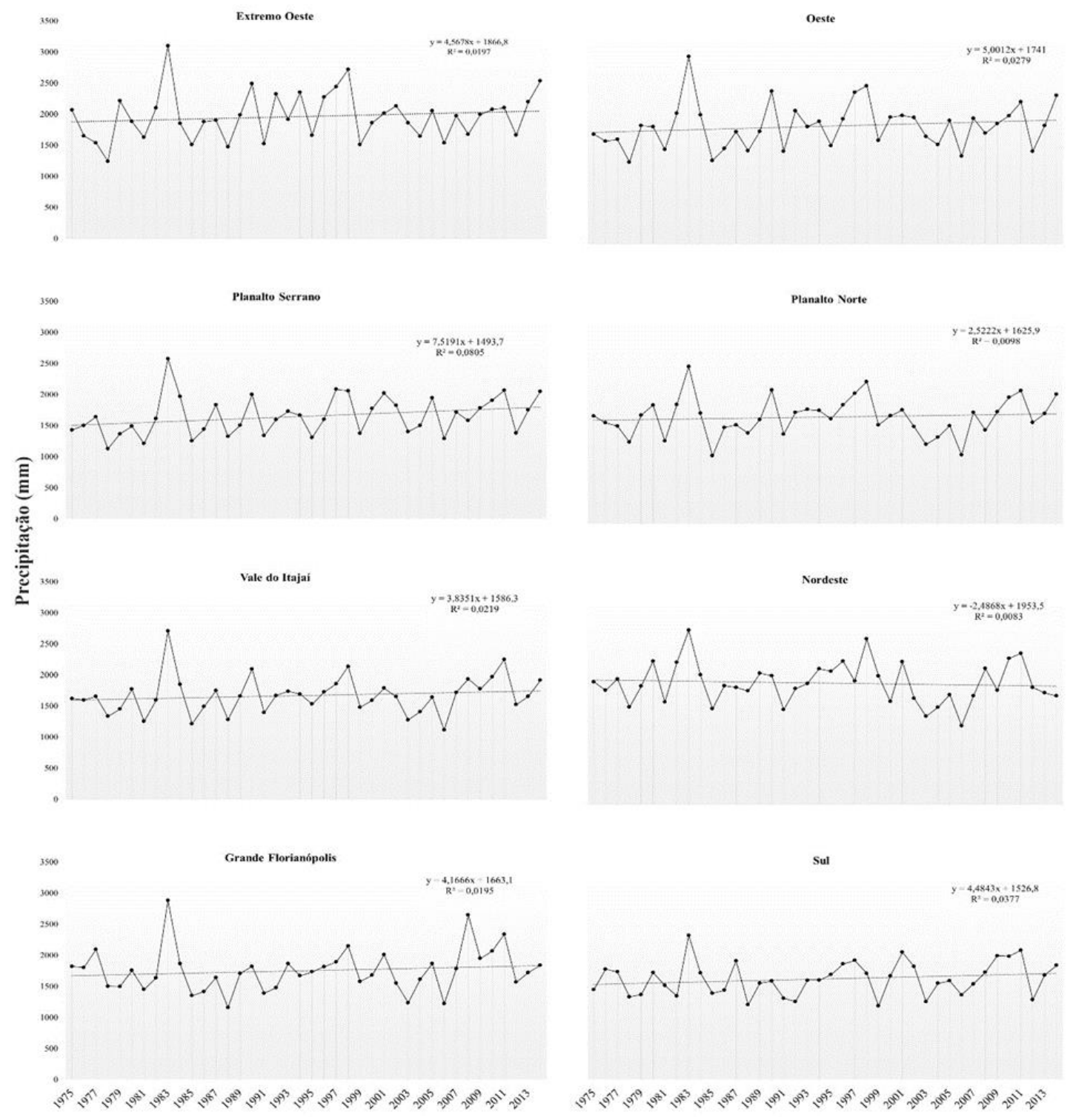

O maior aumento pela linha de tendência foi para as regiões Leste e Sul e o menor para o Extremo Oeste. Resultados são condizentes com as projeções realizadas por Groisman et al. (2005), Salati et al. (2007) e Marengo et al. (2009, que estudaram tendências de precipitação na região Sul do Brasil. Analisando o desvio padrão foi possível determinar um desvio de $\pm 269,9$ 
mm para o Sul e $\pm 295,6 \mathrm{~mm}$ para o Planalto Norte. É interessante ressaltar o Extremo Oeste com um desvio de $\pm 380,23 \mathrm{~mm}$ demonstrando a variação da precipitação na mesorregião, determinada por dois períodos distintos, úmido no verão e seco no inverno.

De acordo com os cenários de interpolação da precipitação no estado, pode-se perceber duas regiões distintas em relação às médias das precipitações (Figura 7). 
Figura 7 - Estimativa da precipitação, cenários: (A) 1975-1984; (B) 1985-1994; (C) 19952004; (D) 2005-2014; (E) 2015-2024; e (F) média geral, Santa Catarina.

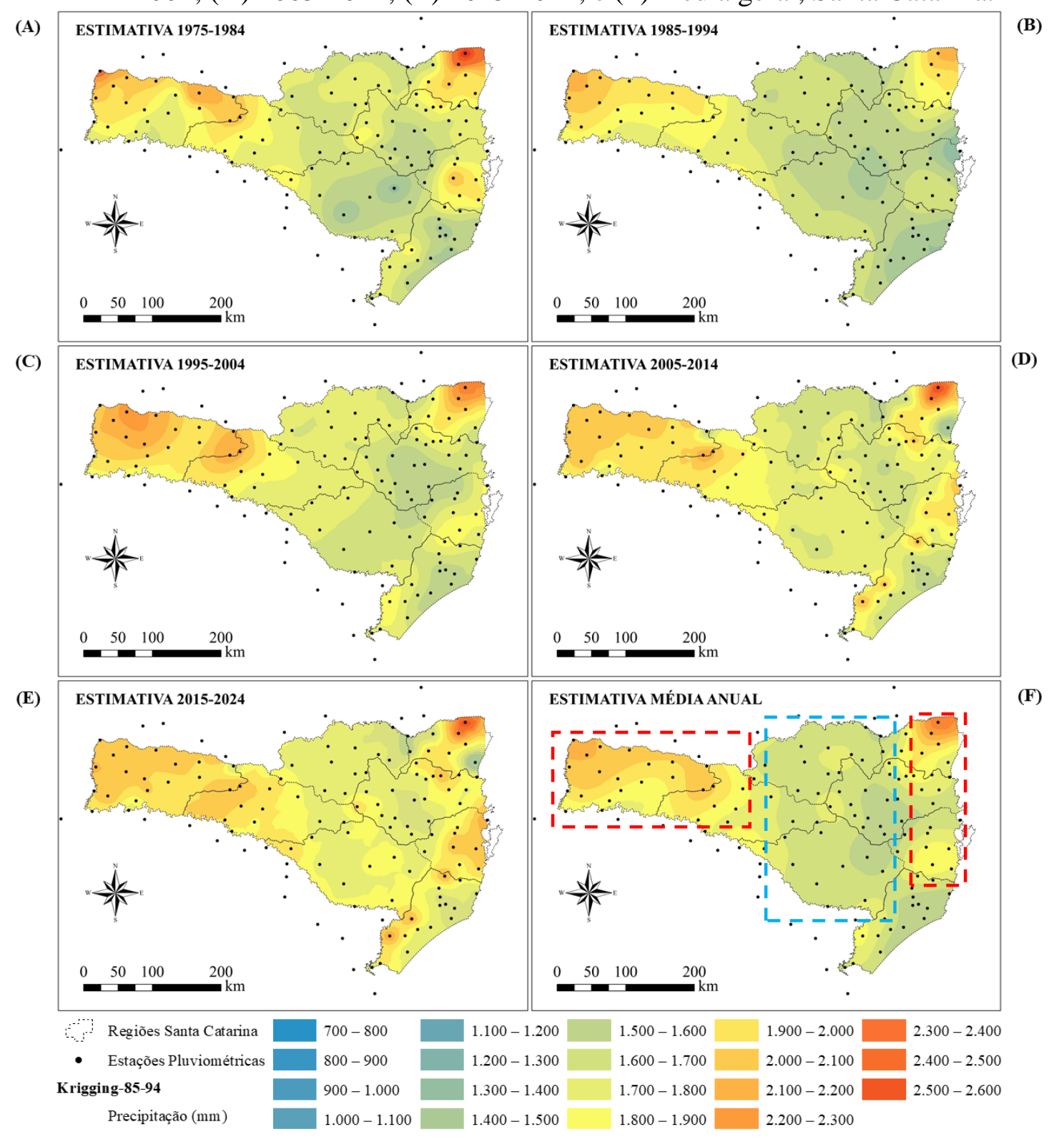

De forma geral, a região do Extremo Oeste e Oeste apresentam elevados índices pluviométricos. A região do Planalto e a cabeceira do Vale do Itajaí são marcadas pelos menores índices pluviométricos. A região Nordeste e Leste também foram marcadas por altos índices pluviométricos devido às condições geomorfológicas já explicadas (chuvas orográficas). Este 
fato já foi evidenciado também por Monteiro e Furtado (1995) em um estudo do clima da região costeira de Santa Catarina e Rio Grande do Sul, onde os autores afirmam que o relevo catarinense influencia diretamente na distribuição da precipitação, considerando que as maiores precipitações ocorrem nas áreas próximas às encostas das montanhas. Os resultados obtidos através da análise geoestatística na Figura 7 é em parte confirmado pelo resultado da análise de agrupamentos (Figura 8). As regiões do Extremo Oeste e Oeste foram agrupadas, assim como a região Nordeste e Leste, pertencem pelo método de Ward ao mesmo subgrupo. Já as regiões Planalto Norte e Vale do Itajaí, formaram o grupo principal, que foi agrupado sequencialmente com o Planalto Serrano e com a região Sul.

Figura 8 - Análise de agrupamento das regiões de acordo com as médias mensais das

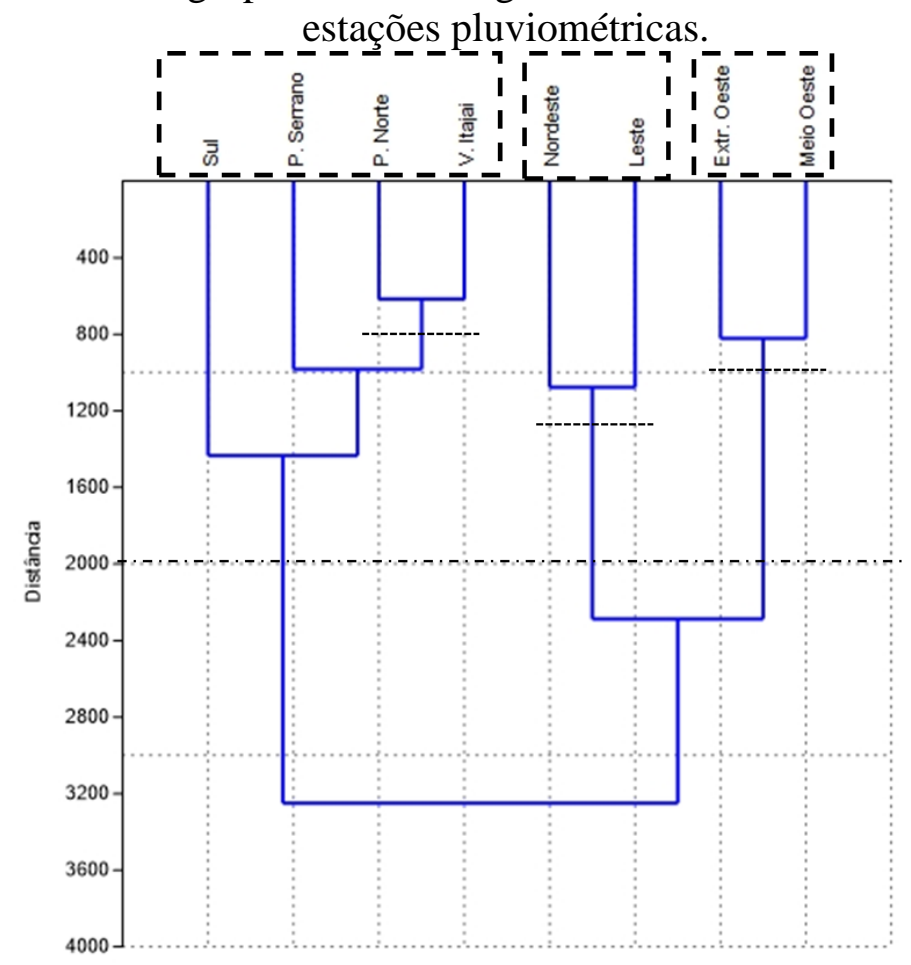

Em síntese, é possível afirmar que existe um aumento das precipitações no Estado de Santa Catarina. As regiões Oeste (aumento de 8,4\% para os próximos 20 anos) e Planalto Serrano (aumento de 12,8\% para os próximos 20 anos) vão enfrentar altos índices de 
precipitação nos próximos anos, assim como as regiões Leste (aumento de 10,5\% para os próximos 20 anos) e Sul (aumento de 12,4\% para os próximos 20 anos). As regiões Extremo Oeste (aumento de 4,7\% para os próximos 20 anos), Planalto Norte (aumento de 4,1\% para os próximos 20 anos) e Vale do Itajaí (aumento de 5,1\% para os próximos 20 anos) também tiveram índices positivos. A única região com tendência negativa foi a região Nordeste (diminuição de 1,8\% para os próximos 20 anos), ficando sobre aviso para possíveis diminuições dos índices pluviométricos nos próximos anos. Tendo em vista os meses do ano, foi possível identificar um aumento elevado da precipitação para os meses de janeiro, abril, junho e setembro. Tendências positivas menos significativas foram encontradas para os meses de fevereiro, março, outubro e dezembro. Os meses com tendência negativa são maio, junho, agosto e novembro.

\section{CONSIDERAÇÕES FINAIS}

O estudo realizado fez a análise integrada dos dados de precipitação demonstrando quais as mesorregiões de Santa Catarina possuem tendência em relação a precipitação, tendo em vista o período de 1975-2014. Diante dos resultados, conclui-se:

- As regiões Oeste e Extremo Oestes foram as responsáveis pelos maiores índices pluviométricos tanto em escala mensal como anual;

- O verão e a primavera foram às responsáveis pelos maiores índices pluviométricos;

- Precipitações apresentaram tendência de aumento para sete das oito mesorregiões, para os dados anuais;

- Os mapas de krigagem forneceram a distribuição do comportamento dos índices pluviométricos do estado, demonstrando as áreas de mudança do clima;

- O comportamento anual da precipitação no estado é bianual, alternando a cada dois anos entre períodos secos e úmidos. 


\section{REFERENCIAS BIBLIOGRÁFICAS}

ANDRADE, A. R.; BALDO, M. C.; NERY, J. T. Variabilidade sazonal da precipitação pluviométrica de Santa Catarina. Acta Scientiarum, v. 21, n. 4, p. 923-928, 1999.

ASSAD, E. D.; LUCHIARI Jr., A. A future scenario and agricultural strategies against climatic changes: the case of tropical savannas. In: Mudanças Climáticas e Estratégias Futuras. USP. Outubro de 1989. São Paulo.

AUMOND, J. J.; SEVEGNANI, L. Medidas de estabilização de encostas. Desastre de 2008 no Vale do Itajaí. Água, gente e política. Frank, B., Sevegnani, L. (Org.). Blumenau: Agência de Água do Vale do Itajaí, 192 p. 2009.

BACK, A. J. Frequência de chuvas em Santa Catarina. Ambiente, Criciúma, v.7, n.2, p. 63-72, jul/dez. 2001.

BACK, A. J.; MIGUEL, L. P.; ZAMBRANO, G. J. D.; LADWIG, N. I. Variação espacial da chuva máxima diária no estado de Santa Catarina. Revista Iniciação Científica, Criciúma, v. 14, n. 1, 2016.

BALDO, M. C.; NERY, J. T.; MARTINS, M. L. O. F. Aspectos estatísticos da precipitação na bacia do Itajaí-Santa Catarina. In: Congresso Brasileiro de Metereologia, 10., 1998, Brasília. Anais... Brasília: CBMET.

BIGGS, E. M.; ATKINSON, P. M. A characterization of climate variability and trends in hydrological extremes in the Severn Uplands. International Journal of Climatology, v. 31, p. 1634-1652, 2011.

BLAIN, G. C. Considerações estatísticas relativas a oito séries de precipitação pluvial da Secretaria de Agricultura e abastecimento do estado de São Paulo. Revista Brasileira de Meteorologia, v. 24, n. 1, p.12-23, 2009.

EMBRAPA - Empresa de Brasileiro de Pesquisa Agropecuária. Aquecimento global e a nova geografia da produção agrícola no Brasil. São Paulo, 2008. Disponível em:<WWW.embrapa.br/publicacoes/tecnico/aquecimentoglobal.pdf $>$. Acesso em: 29 agos. 2016.

FOLHES, M. T.; FISCH, G. Caracterização climática e estudo de tendência nas séries temporais de temperatura do ar e precipitação em Taubaté (SP). Ambi-Agua, Taubaté, v. 1, n. 1, p.61-71, 2006.

GRIMM, A. M.; FERRAZ, S. E. T.; GOMES, J. Precipitation anomalies in 107 Southern Brazil associated with El Niño and La Niña events. Journal of Climate, v. 11, n. 11, p. 2863-2880, 1998.

GROISMAN, P. Y..; KNIGHT, R. W.; EASTERLING, D. R.; KARL, T. R.; HEGERL, G. C.; RAZUVAEV, V. N. Trends in intense precipitation in the climate record. Journal of Climate, v. 18, n. 9, p. 1326-1350, 2005.

GROPPO, J. D.; MILDE, L. C. E.; GUAMERO, M. E.; MORAES, J. M.; MARTINELLI, L. A. Análise de séries temporais de vazão e de precipitação na Bacia do Rio Piracicaba. Revista de Ciência \& Tecnologia, v. 8, n. 18, p. 109-117, 2001. 
HAIR, J. F.; BLACK, W. C.; BABIN, B. J.; ANDERSON, R. E.; TATHAM, R. L. Análise multivariada de dados. Trad. Adonai S. Sant'Anna e Anselmo Neto. 5 ed. Porto Alegre: Bookman, 2005.

HAMMER, Ø.; HARPER, D. A. T.; RYAN, P. D. PAST: Paleontological statistics software package for education and data analysis. Palaeontologia Electronica, v.4, 2001. Disponível em: http://palaeo-electronica.org/2001_1/past/issue1_01.htm.

HERRMANN, M. L. P. Levantamento dos desastres naturais causados pelas adversidades climáticas no Estado de Santa Catarina, período 1980 a 1995. 1997. 59 f. Tese (Doutorado em Geografia). Universidade Federal de Santa Catarina, 1997.

IBGE - Instituto Brasileiro de Geografia e Estatística. Área Territorial Oficial - Consulta por Unidade da Federação. Arquivado do original em 9 de abril de 2014. Consultado em 20 de fevereiro de 2015.

IPCC - Intergovernmental Panel on Climate Change - Technical Summary. In: Climate Change 2007: The Physical Science Basis. Contribution of Working Group I to the Fourth Assessment Report of the Intergovernmental Panel on Climate Change (IPCC) [Solomon, S., D. Qin, M. Manning, Z. Chen, M. Marquis, K. B. Averyt, M. Tignor and H. L. Miller (eds.)]. Cambridge University Press, United Kingdom and New York, NY, USA, 2007. 996 p.

IPCC - Intergovernmental Panel on Climate Change - Technical Summary. In: Climate Change 2013: The Physical Science Basis. Contribution of Working Group I to the Fifth Assessment Report of the Intergovernmental Panel on Climate Change. Cambridge University Press, Cambridge, United Kingdom New York, 2013.

IPCC - Intergovernmental Panel on Climate Change - Technical Summary. In: Climate Change 2014: Synthesis Report. Contribution of Working Groups I, II and III to the Fifth Assessment Report of the Intergovernmental Panel on Climate Change. IPCC, Geneva, Switzerland, 2014.

KELLER FILHO, T.; ZULLO JUNIOR, J.: LIMA, P. R. S. de R. Análise da transição entre os dias secos e chuvosos por meio da cadeia Markov de terceira ordem. Pesquisa Agropecuária Brasileira, Brasília, v. 41, n. 9, p. 1341-1349, 2006.

MALHOTRA, N. Pesquisa de marketing: uma orientação aplicada. Trad. Laura Bocco. 4 ed. Porto Alegre: Bookman, 2006.

MARCUZZO, F. F. N.; MELO, D. C. R. Distribuição Espaço-Temporal e Sazonalidade das Chuvas no Estado do Mato Grosso. Revista Brasileira de Recursos Hídricos, v. 16, n. 4, p. 157-167, 2011.

MARENGO J. A.; JONES R.; ALVES L.; VALVERDE M. Future change of temperature and precipitation extremes in South America as derived from the PRECIS regional climate modeling system. International Journal Climatology, v. 29, n. 15, p. 2241-2255, 2009.

MARENGO, J. A.; ALVES, L. M. Tendências hidrológicas da bacia do rio Paraíba do Sul. Revista Brasileira de Meteorologia, v. 20, n. 2, p. 215-226, 2005.

MARENGO, J. A.; CHOU, S. C.; KAY, G.; ALVES, L. M.; PESQUERO, J. F.; SOARES, W. R.; SANTOS, D.C.; LYRA, A. A.; SUEIRO, G.; BETTS, R.; CHAGAS, D. J.; GOMES, J. L.; BUSTAMANTE, J. F.; TAVARES, P. Development of regional future climate change 
scenarios in South America using the Eta CPTEC/HadCM3 climate change projections: Climatology and regional analyses for the Amazon, São Francisco and the Parana River Basins. Climate Dynamics, v. 38, p.1829-1848, 2012.

MELLO, C. R.; VIOLA, M. R.; MELLO, J. M.; SILVA, A. M. Continuidade espacial de chuvas intensas no estado de Minas Gerais. Ciência Agrotecnica, v. 32, n. 2, p. 532-539, 2008.

MENDONÇA, F. Aquecimento Global e suas manifestações regionais e locais: alguns indicadores da região Sul do Brasil. Revista Brasileira de Climatologia, v. 2, p.71-86, 2006.

MONTEIRO, M. A. Caracterização climática do estado de Santa Catarina: uma abordagem dos principais sistemas atmosféricos que atuam durante o ano. Geosul, v. 16, n.31, p 69-78, 2001. MONTEIRO, M. A.; FURTADO, S. M. O clima do trecho Florianópolis - Porto Alegre: Uma abordagem dinâmica. Geosul, v. 10, p. 117-133, 1995.

OBREGÓN, G.; MARENGO, J. A. Caracterização do clima no Século XX no Brasil: Tendências de chuvas e Temperaturas Médias Extremas. Relatório $n^{0}$ 2. Ministério do Meio Ambiente. Secretaria de Biodiversidade e Florestas. Diretoria de Conservação da Biodiversidade. 91p. Disponível em: <http://mudancasclimaticas.cptec.inpe.br/ rmclima/pdfs/prod_probio/Relatorio_2.pdf>. Acesso em: 16/06/2010, 2007.

PAIVA, E. M. C. D.; CLARKE, R. T. Análise de tendência de precipitação na Amazônia. Revista Brasileira de Meteorologia, n. 10, p.37-41, 1995.

PANDOLFO, C.; BRAGA, H. J.; SILVA JR, V. P. da; MASSIGNAM, A. M., PEREIRA, E. S.; THOMÉ, V. M. R.; VALCI, F. V. Atlas climatológico do Estado de Santa Catarina. Florianópolis: Epagri, 2002.

PIAZZA, G. A.; TORRES, E.; MOSER, P.; GOTARDO, R.; KAUFMANN, V.; PINHEIRO, A. Análise Espacial e Temporal dos Dados de Precipitação das Estações de Entorno da Bacia do Ribeirão Concórdia, Lontras (SC) Visando Sua Inserção no Contexto de Mudanças Climáticas. Revista Brasileira de Meteorologia, v. 31, n. 4sup, Dec., 2016.

PINTO, H. S.; ASSAD, E. D.; ZULLO Jr., J.; BRUNINI, O.; EVANGELISTA, B. A. Impacto do aumento da temperatura no zoneamento climático do café nos Estados de São Paulo e Goiás: avaliação dos cenários do IPCC. In: CONGRESSO BRASILEIRO DE AGROMETEOROLOGIA; 12., 2001. Fortaleza. Anais... Fortaleza, 2001, p. 605-606.

SALATI, E.; CAMPANHOL, T.; VILA NOVA, N. Caracterização do clima atual e definição das alterações climáticas para o território brasileiro ao longo do Século XXI. Relatório 4. Tendências de Variações Climáticas para o Brasil no século XX e Balanços Hídricos para Cenários Climático para o Século XXI. 182 p. 2007.

SALVIANO, M. F; GROPPO, J. D.; PELLEGRINO, G. Q. Análise de tendências em dados de precipitação e temperatura no Brasil. Revista Brasileira de Meteorologia, v. 31, 1, 64-73, 2016.

SANCHES, F. O.; VERDUM, R.; FISCH, G. Tendência de longo prazo das chuvas diárias no sudoeste do Rio Grande do Sul: os eventos extremos e a arenização. Revista Brasileira de Geografia Física, v. 7, n. 6, p. 1100-1109, 2014. 
SANTA CATARINA. Projeto Macrorregiões de Saúde - Plano Estadual de Saúde (PES) Secretaria do Estado da Saúde (SES/SC) - Santa Catarina, 2009. Disponível em: http://www.saude.sc.gov.br/geral/planos/programas_e_projetos/macro/mapa.jpg. Acesso em: 10 de Novembro de 2015.

SELUCHI, M. E.; CHOU, S. C. Synoptic patterns associated with landslide events in the Serra do Mar, Brazil. Theoretical and Applied Climatology, v. 98, p. 67-77, 2009.

SILLMANN, J.; ROECKNER, E. Indices for extreme events in projections of anthropogenic climate change. Climatic Change, v. 86, p. 83-104, 2008.

SINGH, V. P. Elementary Hydrology. Prentice Hall of India: New Delhi., 1994.

SILVA, R. P.; DAYAWANSA, N. D. K. RATNASIRI, M. D. A comparison of methods used in estimating missing rainfall data. The Journal of Agricultural Sciences, v. 3, n. 2, 2007.

SIQUEIRA, O. J. F. de; FARIAS, J. R. B. de; SANS, L. M. A. Potential effects of global climate change for brazilian agriculture and adaptative strategies for wheat, maize and soybean. Revista Brasileira de Agrometeorologia, v. 2, p. 115-129, 1994.

TEIXEIRA, M. S.; SATYAMURTY, P. Dynamical and synoptic characteristics of heavy rainfall episodes in Southern Brazil. Monthly Weather Review, v. 135, p. 598-617, 2007.

VALVERDE, M. C.; MARENGO, J. A. Extreme rainfall indices in the hidrographic basins of Brazil. Open Journal of Modern Hidrology, v. 4, n. 1, p. 10-26, 2014.

VILLARINI, G. Analyses of annual and seasonal maximum daily rainfall accumulations for Ukraine, Moldova, and Romania. International Journal of Climatology, v. 32, p. 2213-2226, 2011.

WANDERLEY, H. S.; CARVALHO, A. L.; FERNANDES, R. C.; SOUZA, J. L. Mudança no Regime Temporal da Temperatura do ar e Precipitação Pluviométrica na região de Rio Largo, Alagoas. Revista Brasileira de Geografia Física, v. 7, 4, p. 662-667, 2014.

WARD, J. H. Hierarquical grouping to optimize an objective function. Journal of the American Statistical Association, v. 58, p. 236 -244, 1963.

Recebido em 15 de janeiro de 2017.

Aceito em 13 de abril de 2018. 